of all infliximab (after 18 months of marketing) and $16 \%$ of etanercept (after 5 months since marketing).

In contrast to the bio-naïve group and those with a history of a previous (but not the same biologic), there was no readily available comparator group for the non-medical switcher group. To this end, we assessed three tentative definitions for a comparator; i) a historical comparison, i.e., same patients 18 months before the switch, ii) an individually matched sample of those patients still on originator treatment at the time of the switch, and iii) the total cohort of those who had not switched.

Conclusions: "Uptake" of biosimilars can be expressed both as proportion of all new starts and as proportion of ongoing treatments. Assessments of uptake, and any comparison between biosimilars and their originators, need to be based on line of therapy in order to avoid mixing up effects of channeling with true differences between originator and similar. For the same reason, any originator comparator for non-medical switchers needs to be reflective of those patients who stood the same chances of switching, but did not switch.

Disclosure of Interest: D. Di Giuseppe: None declared, T. Frisell: None declared, S. Ernestam: None declared, H. Forsblad-d'Elia: None declared, E. Lindqvist: None declared, U. Lindström: None declared, C. Sjöwall: None declared, J. Askling Grant/research support from: Abbvie, BMS, Pfizer, MSD, Roche, Samsung, Lilly DOI: 10.1136/annrheumdis-2017-eular.4651

\section{THU0653 PREVENTING RHEUMATOID ARTHRITIS: A GENERAL POPULATION PILOT STUDY ON PERSPECTIVES OF THE RISK OF DEVELOPING THE DISEASE AND POTENTIAL PREVENTATIVE INTERVENTIONS}

M. Harrison ${ }^{1,2}$, N. Bansback ${ }^{1,2}$, L. Spooner ${ }^{1}$, K. Milbers ${ }^{2}$, C. Koehn ${ }^{3}$, M. Hudson ${ }^{4}$. ${ }^{1}$ University of British Columbia; ${ }^{2}$ Centre for Health Evaluation and Outcome Sciences; ${ }^{3}$ Arthritis Consumer Experts, Vancouver; ${ }^{4}$ McGill University, Montreal, Canada

Background: Evidence suggests that treatment of people at risk of rheumatoid arthritis (RA) with anti-rheumatic drugs could prevent the onset of disease, and there are ongoing randomized controlled trials on the efficacy of preventing RA. However even if these trials are successful, there will be uncertainty around the potential benefits of these programs in practice; namely, the ability to predict those at risk of RA, exact benefits and risks, and inconvenience of treatment. Objectives: To determine the features of a preventative treatment program that are likely to be acceptable to pre-symptomatic people at high risk of RA. Our focus is on preferences for treatment, the values and most important attributes of a preventative treatment program, and the likely uptake of preventative treatment. In this pilot study we sought general population preferences.

Methods: A discrete choice experiment was administered to a US general population sample, asking participants to choose between sets of 2 hypothetical preventative RA treatments, then between their preferred treatment and "no treatment for now". The treatment (risk of developing RA, how treatment is taken, chance of side effects, certainty in estimates, health care provider's opinion) and test attributes (chance test is wrong, who recommends treatment) were identified in focus groups with RA patients, first-degree relatives of RA patients and rheumatologists. An efficient experimental design was developed using SAS and included 2 consistency checks. Responses were analyzed using a conditional logit regression model to estimate the significance and relative importance of attributes in influencing preferences.

Results: 201 respondents completed the survey. The majority of the sample was 25-54 years old (modal age category: $30-39$ years (38\%)) and 50\% were female. 23 members $(11 \%)$ reported having a physician diagnosis of RA, and 91 (45\%) had a family member or close friend with RA. All attributes' levels significantly influenced treatment preferences, but risk reduction, how treatment is taken, and health care provider preference were most influential. Respondents were most willing to trade a reduction in risk of RA for a treatment preferred by their health care professional and an oral route of administration. Respondents had a similar strength of preference for reducing uncertainty in evidence and reducing the risk of side effects. The preferred preventative treatment was chosen over no treatment in $67 \%$ of choices.

Conclusions: Our survey suggests that people value the potential benefits of treatments, but equally values how the treatment is taken and the preference of their health care provider. The degree of confidence in the estimates of a treatment's risks and benefits is as important to people as the risk of side effects. The uptake of a preventative strategy will depend on these key factors. This evidence will help policymakers understand whether different preventative treatment strategies are likely to be acceptable to people they are offered to.

Acknowledgements: This work was supported by a grant from the Canadian Rheumatology Association through the Canadian Initiative for Outcomes in Rheumatology Care (CIORA).

Disclosure of Interest: None declared

DOI: 10.1136/annrheumdis-2017-eular.2170

\section{THU0654 THE INFLUENCE OF RISK PRESENTATION FORMAT ON WILLINGNESS TO START A MEDICATION}

R. Cozmuta $^{1}$, L. Fraenkel ${ }^{2}$, E. Wilhelms ${ }^{3}$, V. Reyna ${ }^{4}$, J. Nolte ${ }^{4} .{ }^{1}$ Emory University, Atlanta; ${ }^{2}$ Yale University, New Haven; ${ }^{3}$ Vasser College, Poughkeepsie, NY; ${ }^{4}$ Cornell University, Ithica, NY, United States

Background: Patients with rheumatoid arthritis frequently refuse to escalate care because they overweight the probability of adverse events. Effectively communicating risk information to patients is difficult. Several approaches have been developed to facilitate comparative risks; however, recent data suggest that current approaches have a limited impact on risk perceptions and willingness to take medication.

Objectives: The objective of this study was to examine whether an icon array (IA), an illustration of the gist of how medications regulate the immune system (a series of balance beams), or both influence willingness to start a medication.

Methods: Patients with a rheumatic disease were mailed a survey in which they were asked to imagine that their symptoms had worsened and that their physician was recommending a new medication. We varied the probability of an adverse event (pneumonia requiring hospitalization): $2 \%$ or $0.2 \%$, and the risk presentation format: numbers, numbers + IA, numbers + balance beams (BB), or numbers + both. Route of administration, benefit, and cost were held constant. Each subject responded to a single, randomly-assigned scenario. We controlled for socioeconomic status (SES), using a variable including both difficulty paying for medications as well as education, in a full-factorial model testing willingness to take the medication (measured on a 5-point scale).

Results: Of 1453 surveys, 465 patients completed the survey. Overall, the mean (SD) age was 59.0 (14.8); $79.7 \%$ were female; $83.2 \%$ White and $39.1 \%$ were classified as having low SES. There were no statistical differences in patient characteristics across the risk presentation formats. Willingness to start the medication was predicted by the interaction between the risk presentation format and SES ( $F=2.9, p=0.03$ ). Willingness by SES status is described in the Figure 1. Among low SES subjects, addition of an IA did not affect willingness compared to the numbers-only format. In contrast, addition of BB (mean difference $=0.47$, $p=0.07$ ), or both IA and BB increased willingness (mean difference $=0.48, p=0.04$ ). Among high SES subjects, addition of an IA or BB or both did not influence willingness compared to the numbers only format. However, both formats including an IA increased willingness compared to the BB format among high SES subjects (mean difference $\mathrm{IA}$ vs $\mathrm{BB}=0.53, \mathrm{p}=0.01$; mean difference $\mathrm{I} A$ vs $\mathrm{IA}+\mathrm{BB}=0.48$, $\mathrm{p}=0.02)$.

Figure 1. Willingness across Formats by SES

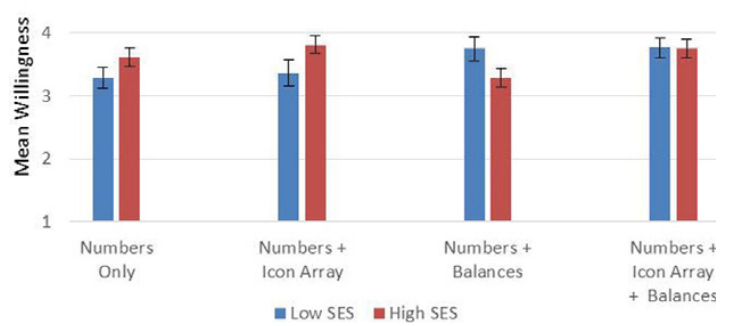

Conclusions: SES affects how subjects respond to risk presentation formats. IA marginally increases willingness in high SES subjects, while BB increases willingness in low SES subjects; when both $I A$ and $B B$ are present, SES differences disappear. BB, when not accompanied by an IA, may decrease willingness in high SES subjects. These results demonstrate the differential effects of risk presentation formats, and highlight the need to identify mechanisms underlying their effects when implementing decision-support tools.

Disclosure of Interest: None declared

DOI: 10.1136/annrheumdis-2017-eular.5169

\section{THU0655 DO VISUAL DECISION AIDS HELP PATIENTS CORRECTLY DIFFERENTIATE BETWEEN A $2 \%$ AND A $0.2 \%$ RISK?}

R. Cozmuta ${ }^{1}$, L. Fraenkel ${ }^{2}$, E. Wilhelms ${ }^{3}$, V. Reyna ${ }^{4}$, J. Nolte ${ }^{4} .{ }^{1}$ Emory University, Atlanta; ${ }^{2}$ Yale University, New Haven; ${ }^{3}$ Vasser College, Poughkeepsie, NY; ${ }^{4}$ Cornell University, Ithica, NY, United States

Background: Studies have found that patients ignore probabilities when making treatment decisions.

Objectives: The objective of this study was to examine whether addition of an icon array (IA), a series of three consecutive balance-beam (BB) illustrations depicting how medications regulate the immune system, or both resulted in patients being able to better differentiate between an uncommon $(2 \%)$ and rare $(0.2 \%)$ adverse event $(\mathrm{AE})$.

Methods: Patients currently being treated for a chronic inflammatory rheumatic disease were mailed a survey in which they were asked to imagine that their symptoms had recently worsened and that their physician was recommending a new medication. The medication was described using eight scenarios (manipulated using a $2 \times 4$ design). We varied the probability of a serious AE (pneumonia 
requiring hospitalization): $2 \%$ vs $0.2 \%$ and the risk presentation format: numbers only, numbers + IA, numbers + BB, and numbers + IA + BB. Route of administration, benefit, and cost were held constant. Each subject responded to a single, randomly-assigned scenario. Dependent variables included perceived riskiness, worry, global gist related to the acceptability of the $\mathrm{AE}$, and willingness to take the medication (all measured on 5-point ordinal scales). We hypothesized that the IA and $\mathrm{BB}$ formats would result in 1) lower perceived riskiness and worry, and 2) greater acceptability of the AE and willingness to take the medication in the $0.2 \%$ vs $2 \%$ scenarios. Socioeconomic status (SES) was defined based on difficulty paying for medication and education level.

Results: We mailed 1453 surveys. 465 patients completed and mailed the survey back (32\% response rate). Overall, the mean age of responders was 58.99 $(\mathrm{SD}=14.85) ; 79.7 \%$ of were female; $83.2 \%$ White and $39.1 \%$ had a low SES. There were no statistical differences in demographic or clinical characteristics across the four risk presentation formats. Mean (SD) perceived riskiness, worry, global gist, and willingness to take the medication for $2 \%$ versus $0.2 \%$ chance of the AE, by SES level, are presented in the Image.

Perceived riskiness was lower for a $0.2 \%$ versus $2 \%$ risk of the $A E$ in the numbers + IA condition in higher SES subjects. Lower SES subjects who viewed both IA and $B B$ were more worried about the $A E$ and found the $A E$ to be less acceptable in the $0.2 \%$ versus $2 \%$ condition.

\begin{tabular}{|c|c|c|c|c|c|}
\hline $\begin{array}{c}\text { Risk } \\
\text { Presentation } \\
\text { Format }\end{array}$ & & $\begin{array}{l}\text { Riskiness } \\
\text { Mean (SD) }\end{array}$ & $\begin{array}{c}\text { Worry } \\
\text { Mean (SD) }\end{array}$ & $\begin{array}{c}\text { Gist } \\
\text { Mean (SD) }\end{array}$ & $\begin{array}{l}\text { Willingness } \\
\text { Mean (SD) }\end{array}$ \\
\hline \multicolumn{6}{|l|}{ Low SES } \\
\hline \multicolumn{6}{|l|}{ Numbers Only } \\
\hline \multirow[t]{3}{*}{ AE probability } & $2 \%$ & $3.12(0.18)$ & $3.16(0.23)$ & $3.12(0.22)$ & $3.20(0.24)$ \\
\hline & $0.20 \%$ & $3.04(0.19)$ & $3.38(0.23)$ & $3.69(0.22)$ & $3.38(0.25)$ \\
\hline & p-value & 0.77 & 0.51 & 0.07 & 0.61 \\
\hline \multicolumn{6}{|l|}{ Numbers + IA } \\
\hline \multirow[t]{3}{*}{ AE probability } & $2 \%$ & $3.4(0.24)$ & $3.4(0.29)$ & $3.07(0.28)$ & $3.20(0.31)$ \\
\hline & $0.20 \%$ & $2.79(0.21)$ & $3.05(0.26)$ & $3.61(0.25)$ & $3.53(0.28)$ \\
\hline & p-value & 0.06 & 0.37 & 0.15 & 0.43 \\
\hline \multicolumn{6}{|l|}{ Numbers + BB } \\
\hline \multirow[t]{3}{*}{ AE probability } & $2 \%$ & $3.06(0.23)$ & $3.13(0.28)$ & $3.32(0.27)$ & $3.69(0.30)$ \\
\hline & $0.20 \%$ & $3.17(0.19)$ & $3.17(0.23)$ & $3.55(0.22)$ & $3.82(0.25)$ \\
\hline & $p$-value & 0.72 & 0.91 & 0.52 & 0.74 \\
\hline \multicolumn{6}{|c|}{ Numbers + $1 \mathrm{~A}+\mathrm{BB}$} \\
\hline \multirow[t]{3}{*}{ AE probability } & $2 \%$ & $2.83(0.17)$ & $2.83(0.21)$ & $3.67(0.2)$ & $4.03(0.22)$ \\
\hline & $0.20 \%$ & $3.20(0.17)$ & $3.40(0.21)$ & $2.99(0.2)$ & $3.50(0.22)$ \\
\hline & p-value & 0.12 & 0.05 & 0.02 & 0.09 \\
\hline \multicolumn{6}{|l|}{ High SES } \\
\hline \multicolumn{6}{|l|}{ Numbers Only } \\
\hline \multirow[t]{3}{*}{ AE probability } & $2 \%$ & $2.95(0.15)$ & $3.03(0.18)$ & $3.52(0.18)$ & $3.50(0.20)$ \\
\hline & $0.20 \%$ & $2.77(0.17)$ & $2.71(0.20)$ & $3.83(0.20)$ & $3.74(0.22)$ \\
\hline & p-value & 0.44 & 0.25 & 0.24 & 0.41 \\
\hline \multicolumn{6}{|l|}{ Numbers + IA } \\
\hline \multirow[t]{3}{*}{ AE probability } & $2 \%$ & $3.29(0.16)$ & $3.06(0.19)$ & $3.61(0.19)$ & $3.82(0.21)$ \\
\hline & $0.20 \%$ & $2.78(0.15)$ & $2.73(0.18)$ & $3.82(0.17)$ & $3.80(0.19)$ \\
\hline & p-value & 0.02 & 0.21 & 0.41 & 0.93 \\
\hline \multicolumn{6}{|l|}{ Numbers + BB } \\
\hline \multirow[t]{3}{*}{ AE probability } & $2 \%$ & $3.25(0.15)$ & $3.43(0.18)$ & $3.48(0.17)$ & $3.43(0.19)$ \\
\hline & $0.20 \%$ & $3.00(0.16)$ & $3.28(0.20)$ & $3.49(0.19)$ & $3.14(0.21)$ \\
\hline & p-value & 0.25 & 0.59 & 0.97 & 0.33 \\
\hline \multicolumn{6}{|c|}{ Numbers $+\mathrm{IA}+\mathrm{BB}$} \\
\hline \multirow[t]{3}{*}{ AE probability } & $2 \%$ & $2.79(0.15)$ & $2.76(0.18)$ & $3.89(0.18)$ & $4.03(0.20)$ \\
\hline & $0.20 \%$ & $3.2(0.17)$ & $3.27(0.21)$ & $3.40(0.2)$ & $3.50(0.22)$ \\
\hline & p-value & 0.07 & 0.07 & 0.07 & 0.08 \\
\hline
\end{tabular}

Conclusions: With the exception of the IA's impact on perceived riskiness among subjects with higher SES, the risk formats used did not enable subjects to correctly differentiate between a $0.2 \%$ and a $2 \%$ risk of a serious $\mathrm{AE}$. These results highlight the lack of impact of quantitative risk information on patients' risk perceptions.

Disclosure of Interest: None declared

DOI: 10.1136/annrheumdis-2017-eular.5618

\section{THU0656 ETANERCEPT BIOSIMILAR USAGE AND ASSOCIATED COST SAVINGS IN GERMANY}

K. Thakur, A. Handrich, E. Psachoulia. Biogen, Zug, Switzerland

Background: The first etanercept biosimilar was approved by the European Commission in January 2016. Of the 27,000 patients $^{*}$ estimated to be treated with etanercept biosimilar in the Europe, 5,122 patients $^{*}$ are estimated to be on the etanercept biosimilar in Germany at the end of the analysis period. Its usage in Europe may support healthcare sustainability by reducing costs, thereby relieving the burden on healthcare budgets and improving patient's ability to get the right care at the right time.

Objectives: The analysis aimed to estimate the pharmacoeconomic impact of etanercept biosimilar use in Germany between March and December 2016.

Methods: The volume of etanercept biosimilar prescribed in Germany was calculated using sell-out data from retail pharmacies to patients sourced from INSIGHT Health. For this analysis, only the pre-filled syringe (PFS) and pre-filled pen (PFP) presentations of $50 \mathrm{mg}$ etanercept were considered. The biosimilar volume share was calculated by dividing the total etanercept biosimilar $50 \mathrm{mg}$ units prescribed by total etanercept $50 \mathrm{mg}$ units prescribed. The cost savings realized through the use of the biosimilar was calculated using the INSIGHT Health volume data and the pharmacies selling price (source: Lauertaxe) of the etanercept reference product and the etanercept biosimilar. (Note: volume, volume share, patient and price data will be updated at time of presentation to reflect most current impact of etanercept biosimilars use).

Results: Based on 5,122 patients currently estimated to be treated with etanercept biosimilar (volume share of $21.4 \%$ in Dec 2016) in Germany and on the price differential between etanercept biosimilar and the reference product, a total cost saving of 8.8 million EUR was realized during the analysis period. Assuming these patients remain on etanercept biosimilar treatment, a total savings of 21.1 million EUR ${ }^{* *}$ can be returned annually to the healthcare system, compared to using only the reference product. This annual cost savings could be utilized to provide treatment to additional 1,208 patients with etanercept biosimilar.

Table 1. No. of $50 \mathrm{mg}$ Pen/PFS etanercept prescribed: March-Dec 16

\begin{tabular}{lccc}
\hline Product & Pen & PFS & Total \\
\hline Reference product & 318,317 & 580,563 & 898,880 \\
Biosimilar & 71,408 & 40,658 & 112,066 \\
\hline
\end{tabular}

\section{—Cumulative cost saing —Monthly etanercept biosimilar volume share}

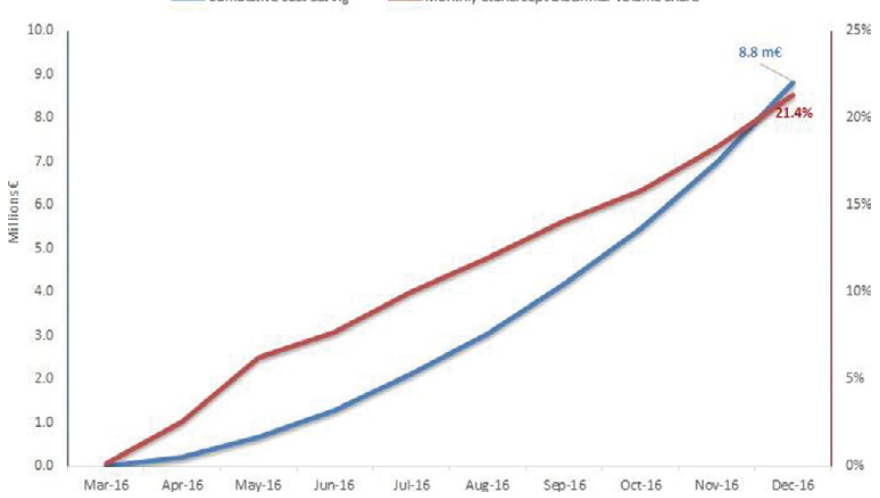

Conclusions: Experience with etanercept biosimilar has been growing in Germany, as reflected by the growing market share. Based on the current number of patients treated with etanercept biosimilar, savings of 21.1 million EUR are projected to be returned to the health system in Germany annually. The economic burden associated with etanercept treatment is expected to decrease further with an increase in market share for the etanercept biosimilar. These savings can have a significant impact on broadening patient access to biologic treatment in Germany.

References:

[1] http://www.ema.europa.eu/.

[2] INSIGHT Health GmbH \& Co.KG.

[3] WHO ATC/DDD classification (final) for etanercept in: WHO Drug Information Vol 15, No 2, 2001.

Disclosure of Interest: K. Thakur Shareholder of: Biogen, Grant/research support from: Biogen, Employee of: Biogen, A. Handrich Shareholder of: Biogen, Grant/research support from: Biogen, Employee of: Biogen, E. Psachoulia Shareholder of: Biogen, Grant/research support from: Biogen, Employee of: Biogen

DOI: 10.1136/annrheumdis-2017-eular.3380

\section{THU0657 A TELE-HEALTH FOLLOW-UP STRATEGY FOR TIGHT CONTROL OF DISEASE ACTIVITY IN RHEUMATOID ARTHRITIS: RESULTS OF THE NON-INFERIORITY RANDOMISED CONTROLLED TRAIL (THE TERA STUDY)}

A. Thurah ${ }^{1,2}$, K. Steengaard-Pedersen ${ }^{1,2}$, M. Axelsen ${ }^{3}$, U. Fredberg ${ }^{3,4}$, L.M.V. Schougaard $^{5}$, N.H.I. Hjøllund ${ }^{5,6}$, M. Pfeiffer-Jensen ${ }^{1,2}$, T.B. Laurberg ${ }^{1}$, K. Lomborg 6,7, T. Maribo 8,9 . ${ }^{1}$ Department of Rheumatology, Aarhus University Hospital; ${ }^{2}$ Clinical Medicine, Aarhus University, Aarhus; ${ }^{3}$ Diagnostic Centre, Silkeborg Regional Hospital, Silkeborg; ${ }^{4}$ Department of Rheumatology, Odense University Hospital, Odense, ${ }^{5}$ WestChronic, Department of Occupational Medicine, University Clinic, Health, Aarhus University, Herning: ${ }^{6}$ Clinical Epidemiology, Aarhus University; ${ }^{7}$ The Research Programme in Patient Involvement, Aarhus University Hospital; ${ }^{8}$ Defactum, Central Denmark Region;

${ }^{9}$ Department of Public Health, Section for Clinical Social Medicine and Rehabilitation, Aarhus University, Aarhus, Denmark

Background: Despite the increased prevalence of rheumatoid arthritis (RA) in recent years, no studies have yet investigated the effect of monitoring disease activity through a standardized tele-health strategy in patients with RA (1).

Objectives: To test the effect of patient-reported outcome (PRO) based telehealth follow-up for tight control of disease activity in patients with RA, and the differences between tele-health follow-up performed by rheumatologists or rheumatology nurses. 